\title{
Pressure Fluctuations Characteristics of the Stilling Basin with a Negative Step
}

\author{
Guibing HUANG ${ }^{\text {a,1 }}$, Mingjun DIAO ${ }^{\text {a }}$, Lei JIANG ${ }^{\text {a }}$, Chuan'ai WANG ${ }^{\text {a }}$ and Wang JIA ${ }^{\text {a }}$ \\ ${ }^{a}$ State Key Laboratory of Hydraulics and Mountain River Engineering, Sichuan \\ University, Chengdu 610065, China
}

\begin{abstract}
Fluctuating pressure is the main cause of the floor fatigue of the stilling basin with a negative step. Despite investigations of stilling basin with a negative step conducted by many researchers, there is not enough information about the influence of the geometric parameters on fluctuating pressure on the floor. In the present study, fluctuating pressure on the floor of the stilling basin with a negative step was systematically investigated by a total of 85 model tests. The results show that the fluctuating pressure coefficient $C_{p^{\prime}}$ has a process of rapid increase and decrease, and then decreases slowly until it becomes stable, and the maximum fluctuating pressure coefficient $C_{p^{\prime} \max }$ lies in the reattachment zone rather than in the jet impingement area for Type II-jump. The dominant frequency of the fluctuating pressure on the floor shows a decreasing trend along stilling basin. With the increase of the step height, the $C_{p^{\prime} \text { max }}$ presents decreasing trend but $X_{0}^{*}$ where the $C_{p^{\prime} \max }$ occurs increasing trend. While there has on obvious regularity between incident angle and $C_{p^{\prime}}$. Finally, according to the fitting of test data, an empirical formula to calculate $C_{p^{\prime} \max }$ is developed. These research results provide reference for the design of stilling basin with a negative step in engineering applications.
\end{abstract}

Keywords. Fluctuating pressure, stilling basin, negative step, fluctuating pressure coefficient, empirical formula

\section{Introduction}

To reduce the excess kinetic energy of the flow downstream, stilling basins are required as energy dissipators at spillway ends [1-3]. A stilling basin dissipates energy by generating hydraulic jump. Usually, its energy dissipation rate may reach up to $85 \%$ [2]. In addition, it has the advantage of weak fluctuation of downstream flow and no atomization. However, the flow velocity and fluctuating pressure of the standard stilling basin are very high, which may cause scour problems of the floor. Therefore, designers proposed the stilling basin with a negative step. It adds a negative step at the entrance of the stilling basin, so that the spillway end is higher than the stilling basin floor.

${ }^{1}$ Guibing Huang, State Key Laboratory of Hydraulics and Mountain River Engineering, Sichuan University, Chengdu 610065, China; E-mail: guibing_huang@163.com. 
Studies have shown that a stilling basin of hydraulic jump type with a negative step can improve the jump characteristics and to ensure that the hydraulic jump will take place at proper position [4]. Besides, due to the existence of a certain thickness of 'water cushion', the stilling basin with a negative step has a lower bottom velocities than a standard stilling basin, which protects the floor. The aim of this paper is the study of its fluctuating pressure on the floor by hydraulic model tests. The intensity and dominant frequency of the fluctuating pressure of the stilling basin with a negative step are analyzed. The influence of geometric parameters (step depth and incident angle) on the fluctuating pressure characteristics is emphatically discussed. Finally, an empirical formula for the maximum fluctuating pressure coefficient of floor is established.

\section{Review of Literature}

The characteristics of the fluctuating pressure of the standard stilling basin have been studied by several researchers. Toso and Bowers [5], Hassanpour et al. [6] and Fiorotto and Rinaldo [7] studied the statistical structure of turbulent fluctuating pressure at the bottom of hydraulic jumps. Yan et al. [8] deals with statistical analysis of pressure fluctuations at the bottom of spatial hydraulic jumps with abrupt lateral expansions. The first research of stilling basins with negative step has been reported by Moore and Morgan [9]. They classified 4 types of jump which may occur as shown in figure 1. Armenio et al. [10] presented experimental results of the statistical structures of pressure fluctuations at the bottom of hydraulic jumps over a negative step. Riazi et al. [4] analyzed amount of pressure fluctuation in negative step B-jump with rough bed. In China, most of the high-head hydropower stations built in the last 20 years have used stilling basins with a negative step. Generally, most of the researches focus on the hydraulic characteristics of the stilling basin with a negative step [3,11-16]. The study of fluctuating pressure characteristics is lack of systematic experimental investigation. Particularly, the influence of parameter changes on the fluctuating pressure characteristics still needs to be further studied.

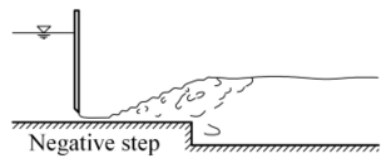

(a) A-jump

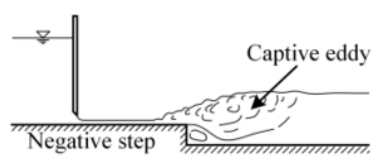

(c) B-jump

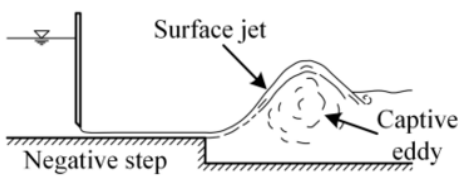

(b) Wave-jump

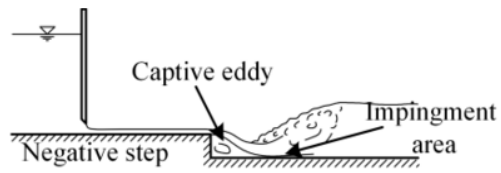

(d) B min-jump

Figure 1. Hydraulic jumps over a negative step. 


\section{Physical Modeling and Experimental Setup}

In this study, the experimental setup consisted of a measuring weir, a reservoir, a spillway, stilling basin with negative step and a circulating water supply. The fluctuating pressure signal of slab in stilling basin was measured by means of a series of piezoresistive pressure sensors (CY200, Test, Inc., China) and the multi-channel hub (RS485-20, Test, Inc., China). The precision of the sensor was $0.1 \%$ of $50 \mathrm{kPa}$ full range, and the multi-channel hub allowed up to 20 sensors to sample simultaneously at a maximum frequency of $1000 \mathrm{~Hz}$. Before each test, the device was calibrated to ensure the reliability of the measurement. The sampling time of this study was 4 minutes and the sampling frequency was $100 \mathrm{~Hz}$. The measurement points were arranged along the centerline of the bottom plate, with a diameter of $2 \mathrm{~mm}$ and an interval $5 \sim 10 \mathrm{~cm}$ [17]. The details of stilling basin with negative step and arrangement of measurement points in the test area are shown in figure 2. In order to study the influence of geometric parameters on the fluctuating pressure characteristics, 16 different stilling basins with a negative step(TP1 TP16) and a standard stilling basin (without a negative step,TP0) were designed in this study, see table 1 . The unit discharge $q$ of each test was varied between $0.02 \mathrm{~m}^{2} / \mathrm{s} \leq q \leq 0.18 \mathrm{~m}^{2} / \mathrm{s}\left(\Delta q=0.04 \mathrm{~m}^{2} / \mathrm{s}\right)$, a total of 85 tests have been carried out.

Table 1. Test plan of stilling basin with negative step.

\begin{tabular}{ccccc|ccccc}
\hline $\begin{array}{c}\text { Test } \\
\text { Plan }\end{array}$ & $D(\mathrm{~m})$ & $\Theta\left({ }^{\circ}\right)$ & $\begin{array}{c}L \\
(\mathrm{~m})\end{array}$ & $C(\mathrm{~m})$ & $\begin{array}{c}\text { Test } \\
\text { Plan }\end{array}$ & $D(\mathrm{~m})$ & $\Theta\left({ }^{\circ}\right)$ & $L(\mathrm{~m})$ & $C(\mathrm{~m})$ \\
\hline TP 0 & 0.000 & 0 & 2.125 & 0.2625 & TP 9 & 0.075 & 0 & 2.125 & 0.2625 \\
TP 1 & 0.025 & 0 & 1.875 & 0.1875 & TP 10 & 0.075 & 5 & 2.250 & 0.2375 \\
TP 2 & 0.025 & 5 & 2.000 & 0.2125 & TP 11 & 0.075 & 10 & 2.375 & 0.2125 \\
TP 3 & 0.025 & 10 & 2.125 & 0.2375 & TP 12 & 0.075 & 15 & 1.875 & 0.1875 \\
TP 4 & 0.025 & 15 & 2.250 & 0.2625 & TP 13 & 0.100 & 0 & 2.250 & 0.2125 \\
TP 5 & 0.050 & 0 & 2.000 & 0.2375 & TP 14 & 0.100 & 5 & 2.375 & 0.1875 \\
TP 6 & 0.050 & 5 & 2.125 & 0.2625 & TP 15 & 0.100 & 10 & 1.875 & 0.2625 \\
TP 7 & 0.050 & 10 & 2.250 & 0.1875 & TP 16 & 0.100 & 15 & 2.000 & 0.2375 \\
TP 8 & 0.050 & 15 & 2.375 & 0.2125 & & & & & \\
\hline
\end{tabular}

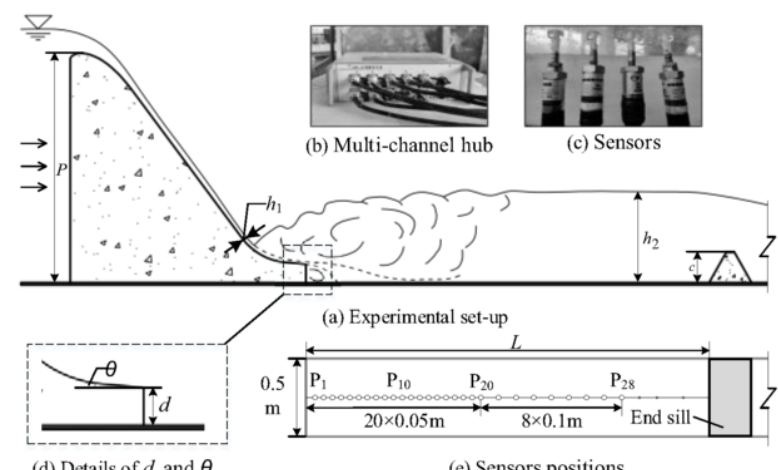

(d) Details of $d$ and $\theta$

(e) Sensors positions

Figure 2. Exteriment setup. 


\section{Experimental Results}

\subsection{Basic Flow Patterns}

Regarding the transition from supercritical to subcritical flow at an abrupt drop, the flow pattern changes with tail-water elevation [10]. The hydraulic condition required to form each flow pattern have been experimentally investigated by Hager and Bretz [13], Ohtsu and Yasuda [11], Armenio and Toscano and Fiorotto [10]. According to the experimental observation, the flow pattern in this study is quite different from the previous studies due to the different geometric shapes of the stilling basin and spillway. Therefore, it is necessary to re-describe the typical flow pattern here. A dimensionless number: flow-energy ratio $k\left(k=q / g^{0.5} H^{1.5}\right)$ is defined here, which can reflect hydraulic conditions in the model. Here, $q$ is unit discharge; $H$ is the water level difference between upstream and downstream; $g$ is the acceleration of gravity.

In this study, two typical flow patterns were observed: Type I-jump (figure 3) and Type II-jump (figure 4). Both Type I-jump and Type II-jump are B-jump. The toe of these two types jump is at the end of the spillway, and the roller lies partly in the sloping and partly in the stilling basin. For relatively low discharge $(k \leq 0.0045)$, Type I-jump happens. For Type I-jump, because the velocity of the main flow is too small, it will not move to the bottom after entering the basin, but will rise up to near the free surface to form a surface flow regime. In the stilling basin, there is also a bottom roll zone near the step. Type I-jump has a very high energy dissipation rate and a nearly horizontal downstream surface profile.

Type II-jump is a mixed flow pattern of submerged inclined jet and submerged hydraulic jump. It mainly occurs in range of $0.0045<k \leq 0.0401$. For Type IIjump, the main flow behaves like a turbulent jet, soon it became a curved jet sandwiched between the surface roller on the top and the captive eddy on the floor [10], and finally it impinges on the floor of the stilling basin. The flow develops as a turbulent wall jet to the end of the surface roller and then gradually transform into a fully developed subcritical flow. According to the characteristics of submerged jet, the floor of the stilling basin can be divided into three sub-regions: reattachment area, jet impingement area and wall attached jet area.

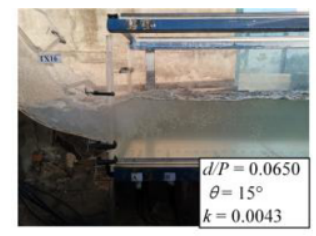

(a) Front view

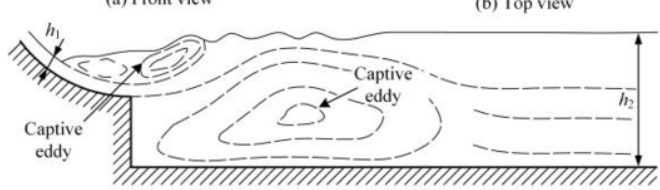

(c) Schematic diagram

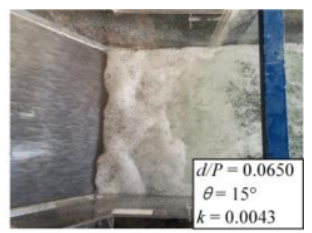

(b) Top view .

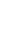




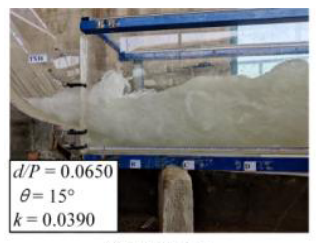

(a) Front view

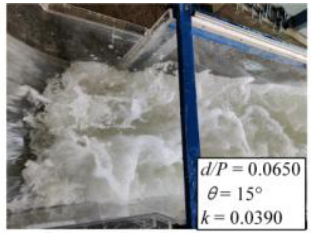

(b) Top view

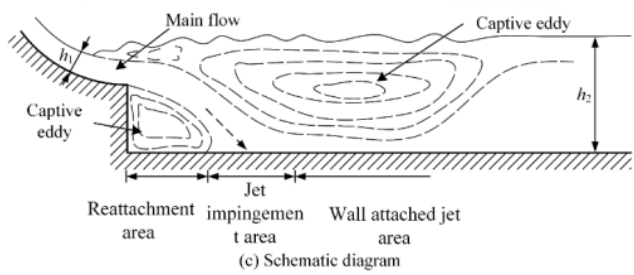

Figure 4. Type II-jump.

\subsection{Intensity Characteristics of Fluctuating Pressure}

Suppose the measured pressure value at a certain point is $p(x, t)$.

Time averaged pressure $\bar{p}$ :

$$
\bar{p}=\lim _{T \rightarrow \infty} \frac{1}{T} \int_{0}^{T} p(x, t) d t
$$

Pressure fluctuation $p^{\prime}$ :

$$
p^{\prime}=p-\bar{p}
$$

Root-mean-square value of pressure fluctuation $\sigma_{p^{\prime}}$ :

$$
\sigma_{p^{\prime}}=\sqrt{\frac{1}{N} \sum_{i=1}^{N}\left(p^{\prime}\right)^{2}}
$$

Fluctuating pressure can give additional information to the dissipation efficiency of a stilling basin in that they have a closely relationship to the turbulence of the water [3]. The dimensionless fluctuating pressure coefficient $C_{p^{\prime}}$ is used to characterize the intensity of fluctuating pressure [18], which is usually defined as:

$$
C_{p^{\prime}}=\frac{\sigma_{p^{\prime}}}{0.5 \rho u_{1}^{2}}
$$


where $u_{1}$ is the incident flow velocity; $\rho$ is the density of water; and $\sigma_{p^{\prime}}$ is the standard deviation of the fluctuating pressure. Typical distributions of the fluctuating pressure coefficient $C_{p^{\prime}}$ on the stilling basin floor are plotted as a function of the dimensionless distance $X^{*}\left(X^{*}=x / L\right)$ in figure 5. For a standard stilling basin, $C_{p^{\prime}}$ coefficient gradually decreases with the increase on $X^{*}$ under the same $k$ number [3]. For a stilling basin with a negative step, the $C_{p^{\prime}}$ coefficient is small when the flow pattern is Type I-jump, because the jump mainly occurs in the end of the spillway, and most of the energy has been dissipated in this zone, so that the intensity of the pulsation in the stilling basin is smaller; when the flow pattern is Type II-jump, $C_{p^{\prime}}$ coefficient increases when the distance from the step increases till it reaches a peak ( $\left.C_{p^{\prime} \max }\right)$, after which it decreases rapidly, then gradually decrease slowly. The special distribution regime of the fluctuating pressure coefficient of Type II-jump is closely related to its own complex flow pattern. Under different $k$ conditions, the distribution of $C_{p^{\prime}}$ remained similarity for Type II-jump. According to the experimental results, $C_{p^{\prime} \max }$ coefficient appears in the reattachment zone rather than in the jet impingement area for Type II-jump. Under the hydraulic conditions of this study $(0.0043<k \leq 0.0401)$, $C_{p^{\prime}}$ coefficient was in the range of $0 \sim 0.10$ for standard stilling basin, and in the range of $0 \sim 0.25$ for a stilling basin with a negative step.

The position corresponding to the maximum fluctuating pressure coefficient $C_{p^{\prime} \max }$ is $X_{0}^{*}$. Table 2 summarizes part of $X_{0}^{*}$ and $C_{p^{\prime} \max }$ in this study. From the table one can observe that: (a) the $C_{p^{\prime} \max }$ coefficient of a standard stilling basin appears in the toe of the hydraulic jump [7]; (b) no matter whether the stilling basin has a negative step, the $C_{p^{\prime} \max }$ coefficient always increases with the increase of $k$; (c) for a stilling basin with a negative step, the dimensionless distance $X_{0}^{*}$ where the $C_{p^{\prime} \max }$ coefficient occurs in creases with increasing $k$ number; and $X_{0}^{*}$ is in the range of $0 \sim$ 0.053 in a $k$ number range between 0.013 and 0.041 .

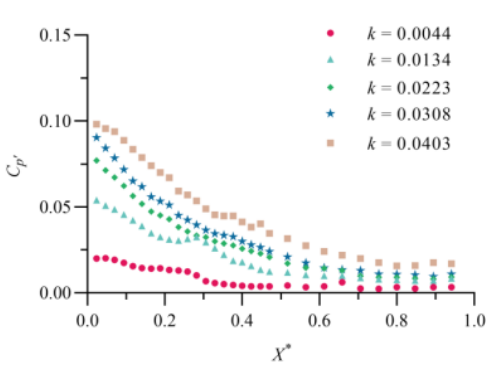

(a) $\operatorname{TP} 0\left(d / P=0, \theta=0^{\circ}\right)$

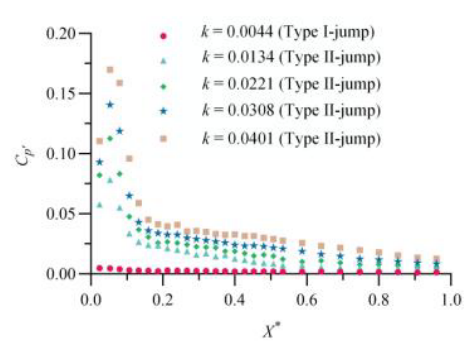

(b) TP9 $\left(d / P=0.049, \theta=0^{\circ}\right)$

Figure 5. Distributions of fluctuation on stilling basin floor. 
Table 2. Relationship of $k, C_{p^{\prime} \max }$ and $X_{0}^{*}$.

\begin{tabular}{llll|llll}
\hline Test Plan & $k$ & $C_{p^{\prime} \max }$ & $X_{0}^{*}$ & Test Plan & $k$ & $C_{p^{\prime} \max }$ & $X_{0}^{*}$ \\
\hline \multirow{4}{*}{ TP 0 } & 0.0044 & 0.0201 & 0.0235 & & 0.0045 & 0.0344 & 0.0267 \\
& 0.0134 & 0.0540 & 0.0235 & & 0.0134 & 0.0805 & 0.0267 \\
& 0.0224 & 0.0770 & 0.0235 & TP 9 & 0.0221 & 0.1151 & 0.0533 \\
& 0.0317 & 0.0904 & 0.0235 & & 0.0308 & 0.1582 & 0.0533 \\
& 0.0404 & 0.0981 & 0.0235 & & 0.0401 & 0.2031 & 0.0533 \\
\hline \multirow{4}{*}{ TP 3 } & 0.0043 & 0.0313 & 0.0235 & & 0.0043 & 0.0046 & 0.0267 \\
& 0.0129 & 0.0982 & 0.0235 & & 0.0130 & 0.0592 & 0.0533 \\
& 0.0213 & 0.1308 & 0.0235 & TP 16 & 0.0215 & 0.0888 & 0.0800 \\
& 0.0299 & 0.1667 & 0.0235 & & 0.0301 & 0.1367 & 0.0800 \\
& 0.0390 & 0.1730 & 0.0235 & & 0.0390 & 0.1654 & 0.0800 \\
\hline \multirow{3}{*}{ TP 6 } & 0.0045 & 0.0344 & 0.0267 & & & & \\
& 0.0134 & 0.0805 & 0.0267 & & & & \\
& 0.0221 & 0.1151 & 0.0533 & & & & \\
\hline
\end{tabular}

\subsection{Dominant Frequency}

From a design viewpoint, the dominant frequency $f_{0}$ of the fluctuating pressure on the floor of the stilling basin are also of interest. The $f_{0}$ can be obtained by power spectral density analysis. Figure 5 shows the distribution of $f_{0}$ in TP0 and TP9. As can be seen from the figure, the dominant frequency of the fluctuating pressure of both TP0 and TP9 shows a decreasing trend along the flow direction. For TP0 (without a negative step), $f_{0}$ is in the range of $0 \sim 6.48 \mathrm{~Hz}$. For TP9 (with a negative step), $f_{0}$ depends on the flow pattern. When the flow pattern is Type I-jump, $f_{0}$ is in the range of $0 \sim 1.98$ $\mathrm{Hz}$; when the flow pattern is Type II-jump, $f_{0}$ is in the range of $0 \sim 6.23 \mathrm{~Hz}$. In general, the dominant frequency of a stilling basin (with or without a negative step) mainly presents a of low-frequency characteristic. At present, it is generally believed that this low-frequency characteristic is associated with large-scale turbulence structures developing within the basin [3]. $f_{0}^{*}$ is defined as the dominant frequency corresponding to $X_{0}^{*}$. Figure 6 shows the scatter plot between the $k$ and $f_{0}^{*}$. As can be seen from figure 7 , for a standard stilling basin, $f_{0}^{*}$ increases with the increase of $k$ value; however, for a stilling basin with a negative step, no clear trends were observed for $f_{0}^{*}$. At the same $k$ value, the $f_{0}$ of a stilling basin with a negative step is smaller than that of a standard stilling basin. 


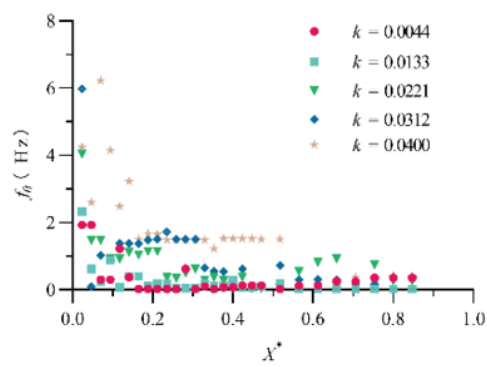

(a) $\operatorname{TP} 0\left(d / P=0, \theta=0^{\circ}\right)$

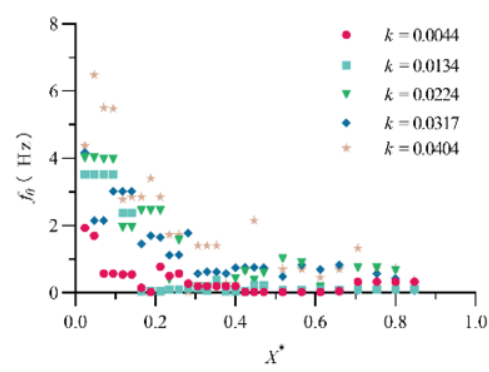

(b) $\operatorname{TP9}\left(d / P=0.049, \theta=0^{\circ}\right)$.

Figure 6. Distributions of dominant frequency on stilling basin floor

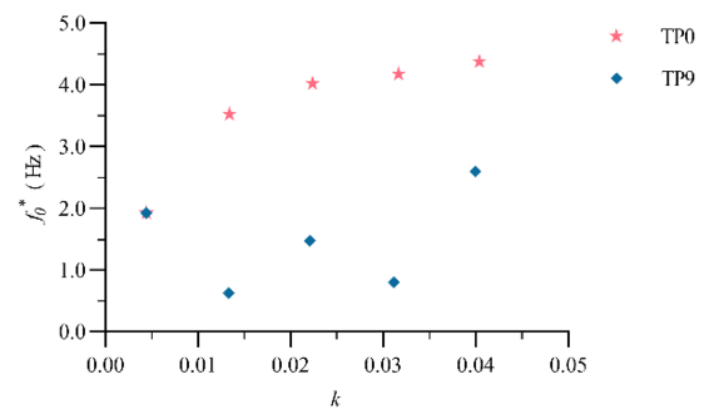

Figure 7. Effect of $k$ number on $f_{0}^{*}$.

\section{Discussion}

\subsection{Effect of Geometric Parameters on Fluctuating Pressure Coefficients}

Figure 8 displays the distribution of $C_{p^{\prime}}$ coefficient against the relative step height $d / P$ and the incident angle $\theta$. According to figure 8 (a), the effect of the step height on $C_{p^{\prime}}$ coefficient is mainly in the range of $0<X^{*}<0.5$. And according to figure 8 (b), the effect of the incident angle on $C_{p^{\prime}}$ coefficient is mainly in the range of $0<X^{*}<0.1$.

Designers also pay great attention to the influence of the variation of geometric parameters on the maximum fluctuating pressure coefficient $C_{p^{\prime} \text { max }}$ and its position $X_{0}^{*}$. The effect of step height and incident angle on the $C_{p^{\prime} \max }$ coefficient and the $X_{0}^{*}$ are shown in figure 9 and figure 10. According to figure 9 , with the increase of step height, $C_{p^{\prime} \max }$ coefficient decreases, but the dimensionless distance $X_{0}^{*}$ increases. The decrease in $C_{p^{\prime} \max }$ is due to the increase in the height of step, which increases the amount of water in the stilling basin that participates in energy dissipation, increases 
the diffusion distance of the submerged jet, and reduces the hydrodynamic pressure on the bottom plate. Calculations show that when the height of the step increases from $d / P$ $=0.016$ to $d / P=0.065$, the $C_{p^{\prime} \max }$ coefficient is reduced by $37.1 \%$. From figure 9 , under different incident angle, no clear trend were observed for $C_{p^{\prime} \max }$ and $X_{0}^{*}$. What needs to be emphasized here is that the plunge point of the submerged inclined jet is not the point where the maximum fluctuating pressure occurs. Although increasing the incident angle, the impact point of the submerged inclined jet will be closer to the step, but it can be seen from figure 10 that $X_{0}^{*}$ did not decrease, but increase.

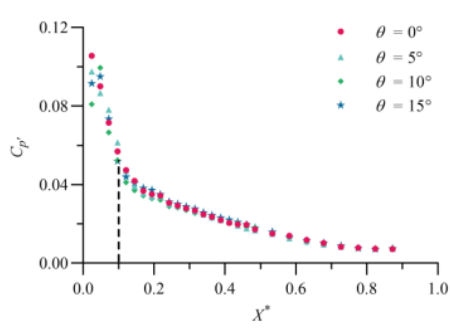

(a) Step heights

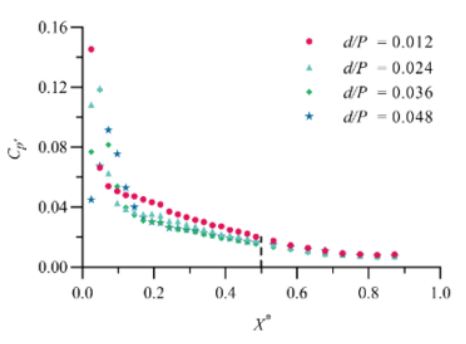

(b) Incident angles

Figure 8. The distributions of fluctuation of different geometric parameters.

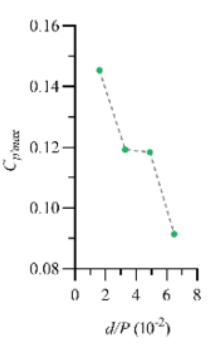

(a) $C_{p^{\prime} \max }$

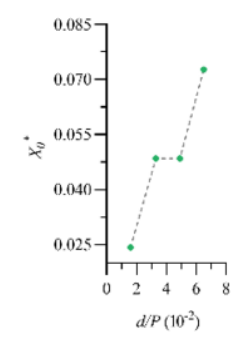

(b) $X_{0}^{*}$

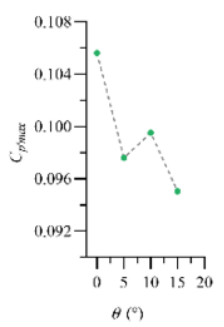

(a) $C_{p^{\prime} \max }$

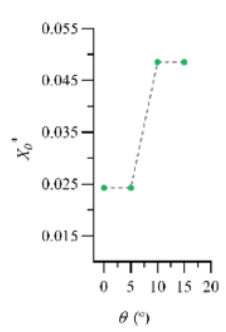

(b) $X_{0}^{*}$

Figure 9. Effect of step height.

\subsection{Empirical Formula of Maximum Fluctuating Pressure Coefficient}

At present, the research on the fluctuating pressure on the floor is still based on the model test, and there is still a lack of a unified theory to explain it. Since the fluctuating pressure coefficient $C_{p^{\prime} \max }$ is an important index to evaluate the safety and stability of the floor of a stilling basin, this section attempts to develop an empirical calculation formula for the $C_{p^{\prime} \text { max }}$ coefficient. According to the model test data, the following calculation formula is finally obtained. 


$$
C_{p^{\prime} \max }=0.28 \operatorname{Exp}\left[-0.14 \sqrt{d h_{2}} /\left(h_{1} / \cos \theta\right)\right]
$$

This formula applies to $7.18 \leq F r_{1} \leq 13.74 ; 0 \leq \theta \leq 15^{\circ} ; d / P=0.016 \sim 0.065$. According to statistical error analysis, the correlation coefficient $R^{2}$ between the predicted value of Equation 6 and the test value is 0.8902 , and the average absolute percentage error $M A P E$ is $17.49 \%$, which meets the engineering needs. Figure 11 shows the comparison between the predicted results and the test results of the maximum fluctuating pressure coefficient.

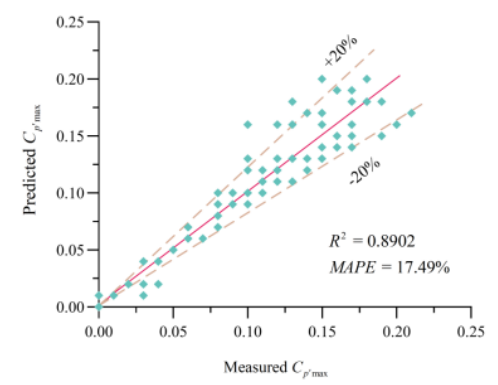

Figure 11. Predicted $C_{p^{\prime} \max }$ against measured $C_{p^{\prime} \max }$.

\section{Conclusions}

The fluctuating pressure characteristics of the floor of the stilling basin with a negative step are closely related to its own stability. In this study, 17 test plans (16 stilling basins with a negative step and 1 standard stilling basin) are designed to study the fluctuating pressure characteristics of the stilling basin with a negative step. In each plan, the fluctuating pressure on the floor of the basin was measured at 5-unit discharges $\left(0.02 \mathrm{~m}^{2} / \mathrm{s} \leq q \leq 0.18 \mathrm{~m}^{2} / \mathrm{s}\right)$, and a total of 85 tests were carried out. According to the experimental results, the effects of the flow-energy ratio $k$ and two key geometric parameters (step height and incident angle) on the characteristics of fluctuating pressure are discussed. The conclusions are as follows:

(a) According to whether the main flow impinges on the floor of stilling basin, two typical flow patterns in the stilling basin with a negative step are defined: Type I-jump pattern and Type II-jump pattern. And the flow processes of these two flow patterns are described respectively.

(b) The distribution of $C_{p^{\prime}}$ in standard stilling basin and stilling basins with a negative step is different. The $C_{p^{\prime}}$ has a process of rapid increase and decrease, and then decreases slowly until it becomes stable. The maximum of fluctuating pressure coefficient $C_{p^{\prime} \max }$ appears in the reattachment zone rather than in the jet impingement zone for Type II-jump in the stilling basin with a negative step. The $C_{p^{\prime} \max }$ in a 
standard stilling basin appears at the toe of the hydraulic jump and gets smaller along the stilling basin.

(c) The dominant frequency of the fluctuating pressure of the stilling basin with (or without) a negative step shows a decreasing trend along the flow direction. When $k$ is in the range of $0.0043 \sim 0.0404$, the dominant frequency of stilling basin with a negative step belongs $0 \sim 6.23 \mathrm{~Hz}$, while standard stilling basin belongs $0 \sim 6.48 \mathrm{~Hz}$, respectively.

(d) The effect of step height on $C_{p^{\prime}}$ mainly concentrate in $0<X^{*}<0.5$, and with the increase of the step height ,the $C_{p^{\prime} \max }$ decreases but $X_{0}^{*}$ increase. And the effect of incident angle on $C_{p^{\prime}}$ in $0<X^{*}<0.1$, and it did not show obvious regularity.

(e) The empirical formula for calculating the maximum fluctuating pressure coefficient is fitted.

\section{Nomenclature}

The following symbols are used in this paper:

$\begin{array}{ll}d & \text { step height }(\mathrm{m}) ; \\ \theta & \text { incident angle }\left({ }^{\circ}\right) ; \\ L & \text { length of stilling basin }(\mathrm{m}) ; \\ c & \text { height of end sill }(\mathrm{m}) ; \\ \bar{p} & \text { time averaged pressure }(\mathrm{Pa}) ; \\ p^{\prime} & \text { pressure fluctuation }(\mathrm{Pa}) ; \\ C_{p^{\prime}} & \text { fluctuating pressure coefficient; } \\ X^{*} & \text { dimensionless distance; } \\ k & \text { flow-energy ratio; } \\ \rho & \text { water density }\left(\mathrm{kg} / \mathrm{m}^{3}\right) ; \\ X_{0}^{*} & \text { the } X^{*} \text { of the } C_{p^{\prime} \text { max }} ; \\ q & \text { unit discharge }\left(\mathrm{m}^{2} / \mathrm{s}\right) ; \\ f_{0} & \text { dominant frequency }(\mathrm{Hz}) ; \\ f_{0}^{*} & \text { the } f_{0} \text { of } X_{0}^{*}(\mathrm{~Hz}) ; \\ u_{1} & \text { incident flow velocity }(\mathrm{m} / \mathrm{s}) ; \\ g & \text { acceleration of gravity }\left(\mathrm{m}^{2} / \mathrm{s}\right) ; \\ H & \text { water level difference between upstream and downstream }(\mathrm{m}) ; \\ \sigma_{p^{\prime}} & \text { root-mean-square value of pressure fluctuation; } \\ C_{p^{\prime} \text { max }} & \text { the maximum fluctuating pressure coefficient; }\end{array}$




\section{Reference}

[1] Macián-Pérez JF, García-Bartual R, Huber B, Bayon A and Vallés-Morán FJ. Analysis of the flow in a typified USBR II stilling basin through a numerical and physical modeling approach. Water. 2020 Jan; 12(1): 227.

[2] Stojnic I, Pfister M, Matos J and Schleiss AJ. Effect of 30-Degree sloping smooth and stepped chute approach flow on the performance of a classical stilling basin. Journal of Hydraulic Engineering. 2021 Dec; 147(2): 04020097.

[3] Padulano R, Fecarotta O, Del Giudice G and Carravetta A. Hydraulic design of a USBR Type II dtilling basin. J. Irrig. Drain. Eng. 2017 Jan; 143(5): 04017001.

[4] Riazi R, Bejestan MS and Motlaq KS. Analysis amount of pressure fluctuation in negative step B-jump with rough bed. Journal's URL. 2014 Dec; 4(1): 45-50.

[5] Toso JW and Bowers CE. Extreme pressures in hydraulic-Jump stilling basins. Journal of Hydraulic Engineering. 1988 Aug; 114(8): 829-43.

[6] Hassanpour N, Hosseinzadeh Dalir A, Bayon A and Abdollahpour M. Pressure fluctuations in the spatial hydraulic jump in stilling basins with different expansion ratio. Water. 2020 Dec; 13(1): 60.

[7] Fiorotto V and Rinaldo A. Fluctuations pressure fluctuations under hydraulic jumps. Journal of Hydraulic Research. 1992 Jul; 30(4): 499-520.

[8] Yan ZM and Zhou CT. Pressure fluctuations beneath spatial hydraulic jumps. Journal of Hydrodyn. 2006 Dec; 18(6): 723-6.

[9] Moore WL and Morgan CW. The hydraulic jump at an abrupt drop. Journal of the Hydraulics Division. 1957 Dec; 83(6): 1449-1.

[10] Armenio V, Toscano P and Fiorotto V. On the effects of a negative step in pressure fluctuations at the bottom of a hydraulic jump. Journal of Hydraulic Research. 2000 Sept; 38(5): 359-68.

[11] Ohtsu I and Yasuda Y. Transition from supercritical to subcritical flow at an abrupt drop. Journal of Hydraulic Research. 1991 May; 29(3): 309-28.

[12] Hager WH. B-jump in sloping channel. Journal of Hydraulic Research. 1958 May;26(5):539-58.

[13] Hager WH and Bretz NV. Hydraulic jumps at positive and negative steps. Journal of Hydraulic Research.1986 Aug; 24(4): 237-53.

[14] Ohtsu I, Yasuda Y and Yamanaka Y. Drag on vertical sill of forced jump. Journal of Hydraulic Research, 1991 Jan, 29(1):29-47.

[15] Dong TS. Research on energy dissipation mechanism and fluctuating pressure of special-shaped stilling basin. Tianjin University; 2016.

[16] Li SL. Research on hydrodynamic loads of stilling basin with drop sill. Tianjin University; 2012.

[17] Wei WR, Xu WL, Deng J and Liu B. Experimental study of impact pressures on deep plunge pool floors generated by submerged inclined jets with controlled aeration. Journal of Hydraulic Engineering. 2020 Apr; 146(4): 040200211.

[18] Toso JW and Bowers CE. Extreme pressures in hydraulic-jump stilling basins. Journal of Hydraulic Engineering. 1988 Aug; 114(8): 829-43. 